\title{
Presentations and outcomes of interstitial lung disease and the anti-Ro52 autoantibody
}

\author{
A. Sclafani ${ }^{1 *}\left(\mathbb{D}\right.$, K. M. D'Silva ${ }^{2}$, B. P. Little ${ }^{3}$, E. M. Miloslavsky², J. J. Locascio ${ }^{4}$, A. Sharma ${ }^{3}$ and S. B. Montesi ${ }^{1}$
}

\begin{abstract}
Background: Distinct clinical presentations of interstitial lung disease (ILD) with the myositis-specific antibodies, including anti-synthetase antibodies, are well-recognized. However, the association between ILD and the myositisassociated antibodies, including anti-Ro52, is less established. Our objectives were to compare presenting phenotypes of patients with anti-Ro52 alone versus in combination with myositis-specific autoantibodies and to identify predictors of disease progression or death.

Methods: We performed a retrospective cohort study of 73 adults with ILD and a positive anti-Ro52 antibody. We report clinical features, treatment, and outcomes.

Results: The majority of patients with ILD and anti-Ro52 had no established connective tissue disease (78\%), and one-third had no rheumatologic symptoms. Thirteen patients (17.8\%) required ICU admission for respiratory failure, with $84.6 \%$ all-cause mortality. Of the 73 subjects, $85.7 \%$ had a negative SS-A, and $49.3 \%$ met criteria for idiopathic pneumonia with autoimmune features (IPAF). The 50 patients with anti-Ro52 alone were indistinguishable from patients with anti-Ro52 plus a myositis-specific autoantibody. ICU admission was associated with poor outcomes ( HR 12.97, 95\% Cl 5.07-34.0, $p<0.0001$ ), whereas rheumatologic symptoms or ANA $>=1: 320$ were associated with better outcomes (HR 0.4, 95\% Cl 0.16-0.97, $p=0.04$, and HR 0.29, 95\% Cl 0.09-0.81, $p=0.03$, respectively).

Conclusions: Presentations of ILD with the anti-Ro52 antibody are heterogeneous, and outcomes are similar when compared to anti-Ro52 plus myositis-specific antibodies. Testing for anti-Ro52 may help to phenotype unclassifiable ILD patients, particularly as part of the serologic criteria for IPAF. Further research is needed to investigate treatment of ILD in the setting of anti-Ro52 positivity.
\end{abstract}

Keywords: Interstitial lung disease, Myositis, Antibodies, Interstitial pneumonia with autoimmune features, Connective tissue disease

\section{Background}

Interstitial lung disease (ILD) is a major cause of morbidity and mortality in patients with idiopathic inflammatory myopathies [1-3]. Myositis-associated ILD can present with varying degrees of respiratory compromise and muscle involvement, and may precede a diagnosis of myositis in 13 to $37.5 \%$ of cases $[1,4,5]$. Nevertheless, distinct clinical phenotypes corresponding to individual myositis autoantibodies have been identified. Even amongst the anti-

\footnotetext{
* Correspondence: asclafani1@partners.org

${ }^{1}$ Division of Pulmonary and Critical Care Medicine, Massachusetts General Hospital and Harvard Medical School, 100 Blossom St, Cox 201, Boston, MA 02114, USA

Full list of author information is available at the end of the article
}

synthetase antibodies (e.g. anti-Jo-1, PL-7, PL-12) classically linked with the syndrome of fever, myositis, ILD, arthritis, Raynaud's phenomenon, and mechanic's hands, diverse presentations are described [6-8]. Similarly, several myositis-specific autoantibodies (e.g. anti-Mi-2, TIF1gamma [p155/140], NXP-2, MDA-5) are recognized to have unique associated clinical features; anti-MDA-5, for instance, is often accompanied by skin ulceration and rapidly-progressive ILD that may be sine myositis [4, 9-12].

Less is known, however, about the presentations of ILD and many of the myositis-associated autoantibodies frequently seen in myositis overlap syndromes. One such antibody, the anti-SS-A $52 \mathrm{kD}$ IgG (also known as anti-Ro52),

(C) The Author(s). 2019 Open Access This article is distributed under the terms of the Creative Commons Attribution 4.0 International License (http://creativecommons.org/licenses/by/4.0/), which permits unrestricted use, distribution, and 
is the most common autoantibody detected in patients with idiopathic inflammatory myopathies (estimated to be present in $20-30 \%$ of dermatomyositis/polymyositis), and has been described to co-occur with myositis-specific antibodies, particularly the anti-synthetase antibodies and antiMDA-5 [13-18]. Importantly, the coexistence of anti-Ro52 with myositis-specific autoantibodies is associated with an aggressive ILD course [7, 19, 20].

While anti-Ro52 positivity is seen in many connective tissue diseases (CTDs), reactivity to Ro52 is greater in patients with myositis and systemic sclerosis in contrast to the anti-SS-A $60 \mathrm{kD}$ antibody seen in Sjogren's syndrome and systemic lupus erythematosus [13, 16, 21]. Although frequently conflated as simply "Ro" or "SS-A," Ro52 and Ro60 antigens represent two different proteins, with their corresponding autoantibodies demonstrating distinct clinical associations [13, 22-24]. In one cohort of 247 patients with a high prevalence of CTD, $63 \%$ had a positive anti-Ro52 without anti-Ro60; this antibody profile was associated with pulmonary manifestations in $22 \%$ [24]. However, the diagnostic value of anti-Ro52 remains debated.

Much of the available evidence to date on the clinical associations of anti-Ro52 has been derived from patients with previously known CTD, including myositis, and from patients with positive anti-synthetase or other myositisspecific antibodies. As such, the interpretation of an isolated positive anti-Ro52 antibody is challenging as part of a diagnostic evaluation for ILD, which may be the initial manifestation of, or occur in the absence of, a specific autoimmune syndrome.

We here describe the clinical features and outcomes of 73 patients with a positive anti-Ro52 autoantibody and ILD as the presenting feature. Our study aims are 1) to characterize and describe the clinical characteristics of patients with ILD and a positive anti-Ro52, 2) to compare the presenting phenotypes of patients with anti-Ro52 alone versus in combination with a positive myositisspecific autoantibody, and 3) to identify prognostic predictors associated with ILD progression or death.

\section{Methods}

\section{Study design, setting, and participants}

We performed a retrospective cohort study of all adult patients seen at Massachusetts General Hospital with ILD and a positive anti-Ro52 antibody from January 1, 2015 to August 16, 2018. Patients were identified from a centralized Research Patient Data Registry if they met the following criteria: 1) age greater than 18 years, 2) diagnosis of ILD according to International Classification of Diseases (10th Revision) code J84 (other interstitial pulmonary diseases), and 3) presence of a positive antiRo52 (positive values were indicated by a titer of $\geqq 20$ units on one standard enzyme immunoassay, the
MyoMarker Panel 3, RDL Reference Laboratory ${ }^{1}$ ). Clinical charts of identified patients were reviewed to ensure inclusion criteria were met and the diagnosis of ILD confirmed on imaging. We excluded a total of 5 patients without chest computed tomography (CT) or whose CTs were not consistent with ILD on review by subspecialty thoracic radiologists. This study was approved by the Partners Institutional Review Board.

\section{Data collection}

Clinical data were systematically collected for each patient by one author (A.Sc.) through a review of the electronic medical record. Clinical variables of interest were recorded at the time of anti-Ro52 positivity, including demographics, duration of pulmonary symptoms, intensive care unit (ICU) admission, rheumatologic symptoms, and prior CTD diagnosis. Laboratory results including anti-Ro52 titer by enzyme immunoassay, antinuclear antibody (ANA), SS-A by enzyme-linked immunosorbent assay (ELISA), creatine kinase, aldolase, and myositis-specific autoantibodies including the anti-synthetase antibodies were also collected. When available, lung biopsy histopathology, pulmonary function testing (PFTs), and immunosuppressive or antifibrotic treatments received after anti-Ro52 testing were recorded.

CTs closest to the time of anti-Ro52 positivity were reviewed independently by two thoracic radiologists (A.Sh. and B.P.L.) and categorized by consensus into ILD patterns according to the ATS/ERS classification of the Idiopathic Interstitial Pneumonias [25]. Presence of fibrosis as defined by reticulation, traction bronchiectasis, and/or honeycombing was reported. Two rheumatologists (E.M.M. and K.D.) independently reviewed each medical record and determined by consensus whether patients met accepted society guideline criteria for CTD at the time of anti-Ro52 testing [8, 26-32]. Additionally, patients were classified as meeting criteria for interstitial pneumonia with autoimmune features (IPAF) according to the 2015 ERS/ATS task force research statement [33].

Outcomes were reported at the time of most recent available follow-up for each patient, which was variable and included both inpatient and outpatient evaluations. Improvement was defined by a greater than $10 \%$ increase in forced vital capacity (FVC) on PFTs or clinical improvement (decreased symptoms, improved oxygenation, or hospital discharge) if PFTs were not available, stability by a less than $10 \%$ change in FVC or clinical stability if PFTs were not available, and progression by a greater than $10 \%$ decline in FVC or clinical worsening if PFTs were not available. As

\footnotetext{
${ }^{1}$ MyoMarker Panel 3 (RDL Reference Laboratory) includes the following tests: Anti-Jo-1 Ab, Anti-Mi-2 Ab, Anti-PL-12 Ab, Anti-PL-7 Ab, Anti-EJ Ab, Anti-OJ Ab, Anti-SRP Ab, Anti-Ku Ab, Anti-U2 RNP, Anti-PM/Scl-100 Ab, Anti-MDA5 Ab, Anti-NXP2 Ab, Anti-TIF-1Y Ab, Anti-SSA 52 kD IgG Ab, Anti-U1 RNP Ab, Anti-Fibrillarin U3 RNP Ab. http://www.rdlinc.com/test_menu/myomarker-panel-3/
} 
a primary respiratory cause of death was not able to be identified in many patients with multiorgan failure at the time of death, mortality was reported as all-cause.

\section{Statistical analysis}

Continuous variables are presented as medians with ranges, and categorical variables are summarized as counts and percentages. All statistical tests (Wilcoxon rank-sum test for continuous variables and Chi-squared or Fisher's exact tests for categorical variables) were two-sided. $P$ values less than 0.05 were considered to indicate statistical significance. Corrections for multiple comparisons were applied using the step-down Sidak method. Cox proportional hazards regression was performed predicting time (follow-up days) to poor outcome (disease progression or death). Patients who were stable or improved were censored. A backward elimination algorithm was applied to the predictors age, gender, ICU admission, presence of any rheumatologic symptom, ANA positivity, anti-Ro52 titer, presence of myositisspecific antibodies, fibrosis on imaging, and IPAF criteria met. Statistical analyses were performed using Stata 15.1 (StataCorp) and SAS 9.4 (SAS Institute Inc).

\section{Results}

\section{Clinical features of anti-Ro52 patients}

A total of 73 patients were identified with ILD and a positive anti-Ro52 antibody between January 2015 (when Ro52 testing first became available at our institution) and August 2018. Ages ranged from 23 to 90 years old, with median 68 (Table 1). Thirteen patients (17.8\%) required ICU admission for respiratory failure at the time of antibody testing. One-third of patients had no rheumatologic symptoms on presentation, and nearly one-third experienced myalgias. The majority (78\%) did not carry a prior CTD diagnosis, and only $27.4 \%$ met CTD diagnostic criteria after anti-Ro52 testing. Anti-synthetase syndrome and dermatomyositis/ polymyositis were diagnosed in 5 patients (6.9\%) each. 36 patients (49.3\%) met IPAF criteria.

ANA was negative in $17.8 \%$ of patients and positive at a titer $\geq 1: 320$ in $39.7 \%$ (Table 2). Most patients (85.7\%) were SS-A negative by ELISA. The most common radiographic patterns were nonspecific interstitial pneumonia (NSIP), organizing pneumonia (OP), mixed NSIP/OP, and usual interstitial pneumonia (UIP), with half of patients having $\mathrm{CT}$ evidence of fibrosis. Corticosteroids were the most common pharmacotherapy (given to all patients admitted to the ICU and more than half of non-ICU patients), with half of patients receiving rituximab or mycophenolate either in combination with steroids or as monotherapy (Table 3).

\section{Isolated anti-Ro52 vs anti-Ro52 plus an additional myositis-specific autoantibody}

Fifty of 73 patients (68\%) had an isolated positive antiRo52 (i.e. in the absence of a myositis-specific antibody), and 23 additionally had at least one positive myositisspecific autoantibody, including PL-7 (7 patients), Jo-1 (6 patients), and MDA-5 (5 patients). Other positive antibodies present in two or fewer patients included PL-12, Mi-2, TIF1gamma (p155/140), and NXP-2 (Tables 1 and 2 ). Although there was a trend towards greater prevalence of mechanic's hands, meeting diagnostic criteria for CTD, and higher anti-Ro52 titer in patients with an additional myositis-specific antibody, after correcting for multiple comparisons only a positive cytoplasmic antibody was statistically significantly associated with the presence of an additional positive myositis-specific antibody compared to anti-Ro52 alone $(p=0.002)$.

\section{Predictors of poor outcome}

All-cause mortality was $28.8 \%$. Mortality was largely driven by the $84.6 \%$ mortality of patients admitted to the ICU with respiratory failure at the time of anti-Ro52 testing (Table 3). There was no unadjusted difference in outcomes (disease progression or death) in patients with isolated anti-Ro52 versus with an additional myositisspecific antibody (36\% vs $47.8 \%, p=0.34)$. In Cox proportional hazards regression analysis, admission to an ICU was associated with a higher risk of poor outcome (HR 12.97, 95\% CI 5.07-34.0, $p<0.0001$ ), whereas presence of any rheumatologic symptom or high titer ANA $>=1: 320$ were both associated with a lower risk of poor outcome (HR 0.4, 95\% CI 0.16-0.97, $p=0.04$, and HR $0.29,95 \%$ CI $0.09-0.81, p=0.03$, respectively) (Fig. 1). There was no statistically significant association between poor outcome and radiographic pattern, imaging evidence of fibrosis, or anti-Ro52 titer.

\section{Discussion}

We present the results of the largest, to our knowledge, described cohort of patients with the anti-Ro52 antibody and ILD. While the association of ILD with the myositisspecific antibodies is well-recognized, the association between ILD and the myositis-associated antibodies, including anti-Ro52, is less established. We found that clinical presentations of ILD patients with a positive anti-Ro52 antibody were heterogeneous, ranging from the absence of pulmonary symptoms to hypoxemic respiratory failure with a wide range of ages, men and women, and smokers and non-smokers affected. In our cohort, patients with isolated anti-Ro52 were indistinguishable in presentation and outcomes from patients with anti-Ro52 in combination with myositis-specific autoantibodies. Our results suggest that the presence of a positive anti-Ro52 may have important implications for patients with ILD similar to the presence of a positive myositis-specific antibody.

Prior case series have described an aggressive phenotype of ILD, including worse disease severity and rapid 
Table 1 Demographics and clinical features of patients with ILD and a positive anti-Ro52 antibody. Clinical features were compared between patients with anti-Ro52 alone vs anti-Ro52 plus an additional myositis-specific autoantibody (including anti-Jo-1, anti-PL-12, anti-PL-7, anti-EJ, anti-OJ, anti-Mi-2, anti-SRP, anti-MDA5, anti-NXP2, or anti-TIF-1ץ)

\begin{tabular}{|c|c|c|c|c|c|}
\hline \multirow[t]{2}{*}{ Variable } & \multirow{2}{*}{$\begin{array}{l}\text { All patients } \\
n=73\end{array}$} & \multicolumn{4}{|c|}{ Stratified by Autoantibodies } \\
\hline & & $\begin{array}{l}\text { Isolated Anti-Ro52 } \\
n=50\end{array}$ & $\begin{array}{l}\text { Anti-Ro52 plus } \\
\text { myositis-specific autoAb } \\
n=23\end{array}$ & Raw $p$-value & Adjusted $p$-value ${ }^{*}$ \\
\hline Age, years median [range] & 68 [23-90] & 68.5 [23-90] & 68 [37-83] & 0.75 & 1.0 \\
\hline Male, n (\%) & $45(61.6 \%)$ & $31(62 \%)$ & $14(60.9 \%)$ & 0.93 & 1.0 \\
\hline Ethnicity, n (\%) & & & & 0.53 & 1.0 \\
\hline African American & $7(9.6 \%)$ & $5(10 \%)$ & $2(8.7 \%)$ & & \\
\hline Asian & $6(8.2 \%)$ & $3(6.0 \%)$ & $3(13 \%)$ & & \\
\hline Hispanic & $4(5.5 \%)$ & $2(4.0 \%)$ & $2(8.7 \%)$ & & \\
\hline White & $56(76.7 \%)$ & $40(80 \%)$ & $16(69.6 \%)$ & & \\
\hline Smoking history, n (\%) & & & & 0.43 & 1.0 \\
\hline Current/Former & $43(58.9 \%)$ & $31(62 \%)$ & $12(52.2 \%)$ & & \\
\hline Never & $30(41.1 \%)$ & $19(38 \%)$ & $11(47.8 \%)$ & & \\
\hline Duration of pulmonary symptoms, n (\%) & & & & 0.59 & 1.0 \\
\hline Acute ( $<1$ week) & $9(12.3 \%)$ & $7(14 \%)$ & $2(8.7 \%)$ & & \\
\hline Subacute (1 week-6 mo) & $14(19.2 \%)$ & $8(16 \%)$ & $6(26.1 \%)$ & & \\
\hline Chronic (>6 months) & $48(65.8 \%)$ & $34(68 \%)$ & $14(60.9 \%)$ & & \\
\hline None & $2(2.7 \%)$ & $1(2 \%)$ & $1(4.4 \%)$ & & \\
\hline ICU admission on presentation, n (\%) & $13(17.8 \%)$ & $10(20 \%)$ & $3(13 \%)$ & 0.74 & 1.0 \\
\hline \multicolumn{6}{|l|}{ Rheumatologic symptoms, n (\%) } \\
\hline Myalgias & $23(31.5 \%)$ & $15(30 \%)$ & $8(34.8 \%)$ & 0.68 & 1.0 \\
\hline Mechanic's hands & $10(13.7 \%)$ & $3(6 \%)$ & $7(30.4 \%)$ & 0.01 & 0.24 \\
\hline Gottron's papules & $2(2.7 \%)$ & $1(2 \%)$ & $1(4.4 \%)$ & 0.53 & 1.0 \\
\hline Heliotrope rash & $2(2.7 \%)$ & $2(4 \%)$ & $0(0 \%)$ & 1.0 & 1.0 \\
\hline Other rash & $13(17.8 \%)$ & $7(14 \%)$ & $6(26.1 \%)$ & 0.32 & 1.0 \\
\hline Weight loss & $19(26 \%)$ & $13(26 \%)$ & $6(26.1 \%)$ & 0.99 & 1.0 \\
\hline Raynaud's & $18(24.7 \%)$ & $12(24 \%)$ & $6(26.1 \%)$ & 0.85 & 1.0 \\
\hline Arthralgias & $16(21.9 \%)$ & $10(20 \%)$ & $6(26.1 \%)$ & 0.56 & 1.0 \\
\hline Sicca symptoms & $13(17.8 \%)$ & $9(18 \%)$ & $4(17.4 \%)$ & 1.0 & 1.0 \\
\hline Alopecia & $5(6.8 \%)$ & $4(8 \%)$ & $1(4.4 \%)$ & 1.0 & 1.0 \\
\hline Scleroderma/dactyly & $7(9.6 \%)$ & $6(12 \%)$ & $1(4.4 \%)$ & 0.42 & 1.0 \\
\hline Any rheum symptoms & 49 (67.1\%) & $35(70 \%)$ & $14(60.9 \%)$ & 0.44 & 1.0 \\
\hline None & $24(32.9 \%)$ & $15(30 \%)$ & 9 (39.1\%) & 0.44 & 1.0 \\
\hline Prior CTD diagnosis, n (\%) & & & & 0.97 & 1.0 \\
\hline RA & $1(1.4 \%)$ & $1(2 \%)$ & $0(0 \%)$ & & \\
\hline Sjogren's & $3(4.1 \%)$ & $2(4 \%)$ & $1(4.4 \%)$ & & \\
\hline Scleroderma & $4(5.5 \%)$ & $3(6 \%)$ & $1(4.4 \%)$ & & \\
\hline SLE & $3(4.1 \%)$ & $2(4 \%)$ & $1(4.4 \%)$ & & \\
\hline DM/PM & $2(2.7 \%)$ & $1(2 \%)$ & $1(3.7 \%)$ & & \\
\hline MCTD & $3(4.1 \%)$ & $3(6 \%)$ & $0(0 \%)$ & & \\
\hline None & $57(78 \%)$ & $38(76 \%)$ & 19 (82.6\%) & & \\
\hline Met diagnostic criteria for a CTD, n (\%) & & & & 0.02 & 0.48 \\
\hline Anti-synthetase & $5(6.9 \%)$ & $0(0 \%)$ & $5(21.7 \%)$ & & \\
\hline
\end{tabular}


Table 1 Demographics and clinical features of patients with ILD and a positive anti-Ro52 antibody. Clinical features were compared between patients with anti-Ro52 alone vs anti-Ro52 plus an additional myositis-specific autoantibody (including anti-Jo-1, anti-PL-12, anti-PL-7, anti-EJ, anti-OJ, anti-Mi-2, anti-SRP, anti-MDA5, anti-NXP2, or anti-TIF-1ץ) (Continued)

\begin{tabular}{|c|c|c|c|c|c|}
\hline \multirow[t]{2}{*}{ Variable } & \multirow{2}{*}{$\begin{array}{l}\text { All patients } \\
n=73\end{array}$} & \multicolumn{4}{|c|}{ Stratified by Autoantibodies } \\
\hline & & $\begin{array}{l}\text { Isolated Anti-Ro52 } \\
n=50\end{array}$ & $\begin{array}{l}\text { Anti-Ro52 plus } \\
\text { myositis-specific autoAb } \\
n=23\end{array}$ & Raw $p$-value & Adjusted $p$-value* \\
\hline DM/PM & $5(6.9 \%)$ & $3(6 \%)$ & $2(8.7 \%)$ & & \\
\hline MCTD & $3(4.1 \%)$ & $3(6 \%)$ & $0(0 \%)$ & & \\
\hline PMR & $1(1.4 \%)$ & $1(2 \%)$ & $0(0 \%)$ & & \\
\hline SLE & $2(2.7 \%)$ & $1(2 \%)$ & $1(4.4 \%)$ & & \\
\hline Scleroderma & $4(5.5 \%)$ & $3(6 \%)$ & $1(4.4 \%)$ & & \\
\hline None & $53(72.6 \%)$ & $39(78 \%)$ & $14(60.9 \%)$ & & \\
\hline Met IPAF criteria, n (\%) & $36(49.3 \%)$ & 27 (54\%) & $9(39.1 \%)$ & 0.24 & 1.0 \\
\hline
\end{tabular}

${ }^{*}$ Corrected for multiple comparisons using the step-down Sidak method

progression, in patients with anti-synthetase antibodies co-existing with anti-Ro52 [7, 19]. Our findings suggest that anti-Ro52 alone is associated with similar outcomes when compared to anti-Ro52 in combination with myositis-specific antibodies. Similar to other reports, the imaging and histopathologic patterns of NSIP and organizing pneumonia seen in our cohort reflect recognized patterns associated with ILD in the idiopathic inflammatory myopathies and other CTDs [1, 8, 34]. Additionally, we found that the presence of positive cytoplasmic antibodies in the myositis-specific group was the only statistically significant difference between these patients and those with anti-Ro52 alone. Cytoplasmic staining on immunofluorescence found during ANA testing has been described in anti-synthetase syndrome and should alert clinicians to test for myositis antibodies particularly in the context of ILD $[9,35]$.

Published evidence suggests that as much as $20 \%$ of anti-Ro52 or Ro60 reactivity can be missed when testing for this with many commercially-available SS-A ELISAs that are based on a mixture of both the $60 \mathrm{kD}$ and $52 \mathrm{kD}$ antigens [22]. The observation that diagnostic assays using blended antigens may not detect single reactivity to either antigen has led to recommendations to test for each separately [22-24]. As the vast majority (more than $85 \%$ ) of patients in our cohort were antiRo52 positive by enzyme immunoassay but SS-A/Ro negative by ELISA, our data confirms that many Ro52 positive patients may be missed if SS-A via combination ELISA is used for screening. This is especially relevant given that "anti-Ro (SS-A)" is part of the serologic domain for interstitial pneumonia with autoimmune features [33]. This classification is increasingly used in research and clinical practice for undifferentiated ILD [36, 37]. Deliberate anti-Ro52 testing may therefore help to phenotype patients with previously unclassifiable ILD. In our cohort only one-fourth of patients met criteria for CTD. Testing for SS-A via ELISA alone would have classified only $30.1 \%$ of patients as having IPAF; thus, specific testing for anti-Ro52 resulted in a net reclassification of 14 patients $(19.2 \%)$, thereby increasing the total number of IPAF patients in this cohort to $36(49.3 \%)$.

We observed a strikingly high mortality, nearly $85 \%$, in the patients that tested positive for anti-Ro52 while in the ICU, suggesting that this is an important group of patients to identify. This mortality rate is more than double that of acute respiratory distress syndrome [38], and closer to that of respiratory failure in idiopathic pulmonary fibrosis than in CTD-associated ILD [39]. Potential explanations for this high mortality are only speculative. We reported all-cause mortality and as such our results may overestimate the number of respiratory-related deaths. While it is not surprising that ICU admission was associated with worse outcome, after controlling for this and other clinically relevant predictors we also found that both presence of rheumatologic symptoms and positive ANA $>=1: 320$ were associated with a lower risk of disease progression or death. Given the small numbers of patients in each treatment category our study was underpowered to investigate whether this was due to any treatment effect, including whether such patients were more likely to receive immunosuppression, and this should be investigated in future studies.

Our study has several important limitations. First, this is a retrospective, single center study with small sample size and variable patient follow-up intervals. A future prospective study to confirm our findings is warranted. Second, we cannot prove causality between the presence of an anti-Ro52 antibody and the presence of ILD since a pathophysiologic mechanism remains unknown; however, this is also true of the anti-synthetase antibodies that are generally accepted 
Table 2 Laboratory profile, imaging, and histopathology of patients with ILD and a positive anti-Ro52 antibody

\begin{tabular}{|c|c|c|c|c|c|}
\hline \multirow[t]{2}{*}{ Variable } & \multirow{2}{*}{$\begin{array}{l}\text { All patients } \\
n=73\end{array}$} & \multicolumn{4}{|l|}{ Stratified by Autoantibodies } \\
\hline & & $\begin{array}{l}\text { Isolated Anti-Ro52 } \\
n=50\end{array}$ & $\begin{array}{l}\text { Anti-Ro52 plus } \\
\text { myositis-specific autoAb } \\
n=23\end{array}$ & Raw $p$-value & Adjusted $p$-value* \\
\hline $\begin{array}{l}\text { Anti-Ro52 titer ( } \mathrm{nl}<20 \text { Units), } \\
\text { median [interquartile range] }\end{array}$ & 59 [31-122] & $44.5[28-98]$ & $108[41-140]$ & 0.01 & 0.25 \\
\hline ANA, n (\%) & & & & 0.07 & 0.85 \\
\hline Negative & $13(17.8 \%)$ & $9(18 \%)$ & $4(17.4 \%)$ & & \\
\hline Positive titer < 1:320 & $31(42.5 \%)$ & $17(34 \%)$ & $14(60.9 \%)$ & & \\
\hline Positive titer $>=1: 320$ & $29(39.7 \%)$ & $24(48 \%)$ & $5(21.7 \%)$ & & \\
\hline $\begin{array}{l}\text { Creatine kinase }(\mathrm{nl}<400 \mathrm{U} / \mathrm{L}) \text {, } \\
\text { median [range] }\end{array}$ & $110[13-13,965](n=63)$ & $102[13-13,965](n=42)$ & $119[21-1774](n=21)$ & 0.73 & 1.0 \\
\hline $\begin{array}{l}\text { Aldolase }(\mathrm{nl}<7.7 \mathrm{U} / \mathrm{L}) \text {, median } \\
\text { [range] }\end{array}$ & $7.90[3.8-273](n=67)$ & $8.0[3.9-273](n=45)$ & $7.15[3.8-45](n=22)$ & 0.25 & 1.0 \\
\hline SS-A ELISA positive, n (\%) & $9(14.3 \%)(n=63)$ & $8(18.2 \%)(n=44)$ & $1(5.3 \%)(n=19)$ & 0.26 & 1.0 \\
\hline Positive cytoplasmic Ab, n (\%) & $17(23.3 \%)$ & $5(10 \%)$ & $12(52.2 \%)$ & $<0.0001$ & 0.002 \\
\hline $\begin{array}{l}\text { Dominant radiographic pattern, } \\
\text { n (\%) }\end{array}$ & & & & 0.93 & 1.0 \\
\hline $\mathrm{OP}$ & $25(34.3 \%)$ & $16(32 \%)$ & $9(39.1 \%)$ & & \\
\hline NSIP & $14(19.2 \%)$ & $10(20 \%)$ & $4(17.4 \%)$ & & \\
\hline UIP & $13(17.8 \%)$ & $8(16 \%)$ & $5(21.7 \%)$ & & \\
\hline Mixed OP/NSIP & $10(13.7 \%)$ & $8(16 \%)$ & $2(8.7 \%)$ & & \\
\hline $\mathrm{HP}$ & $4(5.5 \%)$ & $3(6 \%)$ & $1(4.4 \%)$ & & \\
\hline Sarcoid & $2(2.7 \%)$ & $1(2 \%)$ & $1(4.4 \%)$ & & \\
\hline LIP & $1(1.4 \%)$ & $1(2 \%)$ & $0(0 \%)$ & & \\
\hline DAD & $1(1.4 \%)$ & $1(2 \%)$ & $0(0 \%)$ & & \\
\hline PPFE & $1(1.4 \%)$ & $1(2 \%)$ & $0(0 \%)$ & & \\
\hline Infection/aspiration & $1(1.4 \%)$ & $1(2 \%)$ & $0(0 \%)$ & & \\
\hline Other & $1(1.4 \%)$ & $0(0 \%)$ & $1(4.4 \%)$ & & \\
\hline Fibrosis present, $\mathrm{n}(\%)$ & $37(50.7 \%)$ & $25(50 \%)$ & $12(52.2 \%)$ & 0.86 & 1.0 \\
\hline Lung biopsy pathology, n (\%) & & & & 0.07 & 0.85 \\
\hline $\mathrm{OP}$ & $7(9.6 \%)$ & $5(10 \%)$ & $2(8.7 \%)$ & & \\
\hline NSIP & $3(4.1 \%)$ & $3(6 \%)$ & $0(0 \%)$ & & \\
\hline UIP & $1(1.4 \%)$ & $0(0 \%)$ & $1(4.4 \%)$ & & \\
\hline Mixed OP/NSIP & $3(4.1 \%)$ & $0(0 \%)$ & $3(13 \%)$ & & \\
\hline HP & $1(1.4 \%)$ & $1(2 \%)$ & $0(0 \%)$ & & \\
\hline Sarcoid & $1(1.4 \%)$ & $1(2 \%)$ & $0(0 \%)$ & & \\
\hline No biopsy & $57(78.1 \%)$ & $40(80 \%)$ & $17(73.9 \%)$ & & \\
\hline
\end{tabular}

*Corrected for multiple comparisons using the step-down Sidak method

to be associated with ILD. Third, there are varying estimates of the prevalence of anti-Ro52 in healthy individuals, with the highest estimate approximately $12 \%$ based on a study of 100 subjects [40], and we are unable to provide a true estimate of the prevalence of anti-Ro52 in patients with ILD to determine how this compares to that found in healthy controls. Finally, we were unable to comment on the effect of treatment on outcomes due to our small sample size. Further research is needed to assess the prognostic and treatment implications of ILD in in the setting of a positive anti-Ro52 autoantibody.

\section{Conclusions}

Presentations of ILD with a positive anti-Ro52 antibody are heterogeneous and occur frequently in the absence 
Table 3 Treatment and outcomes of patients with ILD and a positive anti-Ro52 antibody, stratified by ICU vs non-ICU (e.g. hospital or clinic) presentation at the time of anti-Ro52 lab testing. Pharmacotherapy includes all medications given, including in combination. Antifibrotic therapy includes medications approved for the treatment of idiopathic pulmonary fibrosis, including pirfenidone or nintedanib. Mortality is all-cause

\begin{tabular}{|c|c|c|c|}
\hline Variable & $\begin{array}{l}\text { All patients } \\
n=73\end{array}$ & $\begin{array}{l}\text { ICU presentation } \\
n=13\end{array}$ & $\begin{array}{l}\text { Non-ICU presentation } \\
n=60\end{array}$ \\
\hline Age, years median [range] & 68 [23-90] & $60[43-86]$ & 69 [23-90] \\
\hline Male, n (\%) & $45(61.6 \%)$ & $10(76.9 \%)$ & 35 (58.3\%) \\
\hline \multicolumn{4}{|l|}{ Ethnicity, n (\%) } \\
\hline African American & 7 (9.6\%) & $2(15.4 \%)$ & $5(8.3 \%)$ \\
\hline Asian & $6(8.2 \%)$ & $2(15.4 \%)$ & $4(6.7 \%)$ \\
\hline Hispanic & $4(5.5 \%)$ & $0(0 \%)$ & $4(6.7 \%)$ \\
\hline White & $56(76.7 \%)$ & $9(69.2 \%)$ & 47 (78.3\%) \\
\hline \multicolumn{4}{|l|}{ Smoking history, n (\%) } \\
\hline Current/Former & $43(58.9 \%)$ & $10(76.9 \%)$ & $33(55 \%)$ \\
\hline Never & $30(41.1 \%)$ & $3(23.1 \%)$ & $27(45 \%)$ \\
\hline \multicolumn{4}{|l|}{ Pharmacotherapy, n (\%) } \\
\hline Corticosteroids & $45(61.6 \%)$ & $13(100 \%)$ & $32(53.3 \%)$ \\
\hline Rituximab & $19(26.0 \%)$ & $2(15.4 \%)$ & 17 (28.3\%) \\
\hline IVIG & $8(11 \%)$ & $4(30.8 \%)$ & $4(6.7 \%)$ \\
\hline Mycophenolate & $18(24.7 \%)$ & $2(15.4 \%)$ & $16(26.7 \%)$ \\
\hline Cyclophosphamide & $2(2.7 \%)$ & $1(7.7 \%)$ & $1(1.7 \%)$ \\
\hline Antifibrotic & $5(6.9 \%)$ & $0(0 \%)$ & $5(8.3 \%)$ \\
\hline \multicolumn{4}{|l|}{ Outcome, n (\%) } \\
\hline Improved & $12(16.4 \%)$ & $2(15.4 \%)$ & $10(16.7 \%)$ \\
\hline Stable & $32(43.8 \%)$ & & $32(53.3 \%)$ \\
\hline Progressed & $8(11 \%)$ & & $8(13.3 \%)$ \\
\hline Died & $21(28.8 \%)$ & $11(84.6 \%)$ & $10(16.7 \%)$ \\
\hline
\end{tabular}
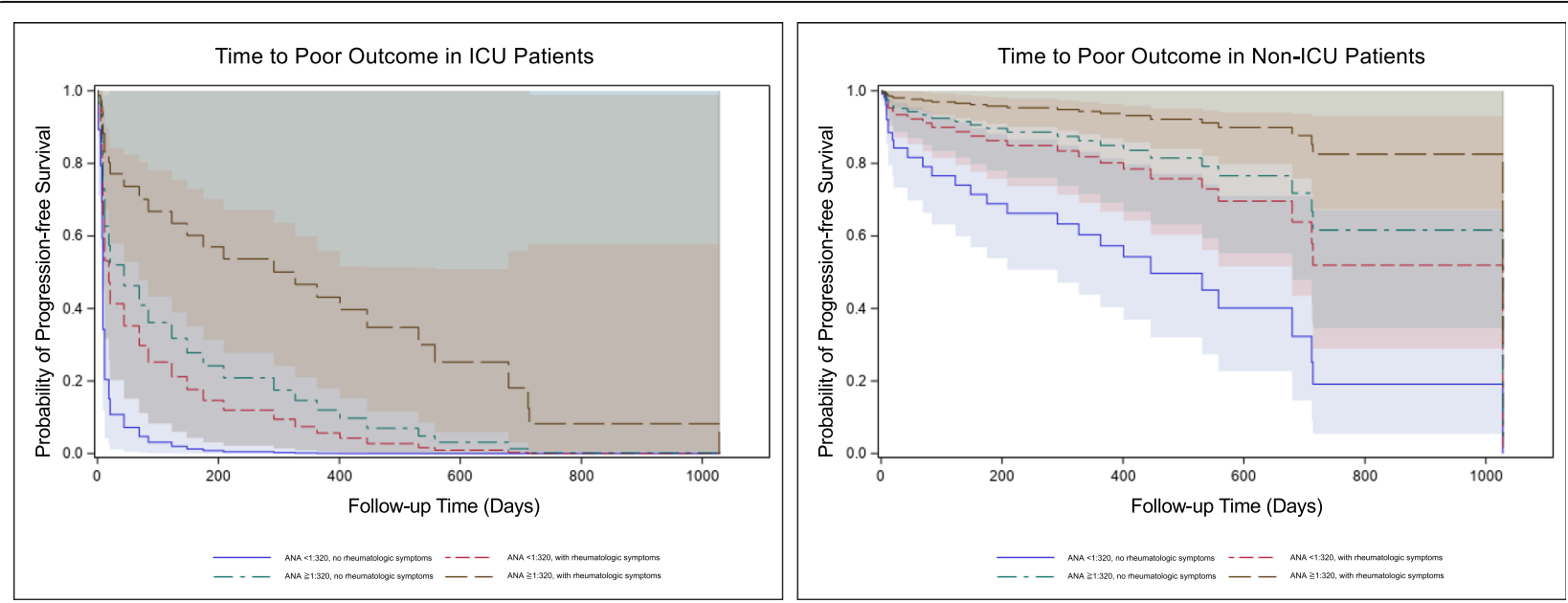

Fig. 1 Kaplan-Meier curves indicating estimated proportion of patients not yet showing a poor outcome (defined as a composite of disease progression or death) versus follow-up days, stratified by ICU admission at the time of anti-Ro52 antibody testing. Admission to an ICU was associated with a higher risk of poor outcome (HR 12.97, 95\% Cl 5.07-34.0, $p<0.0001$ ), whereas presence of any rheumatologic symptom or high titer ANA >= $1: 320$ were associated with a lower risk of poor outcome ( $\mathrm{HR} 0.4,95 \% \mathrm{Cl} 0.16-0.97, p=0.04$, and HR 0.29, 95\% Cl 0.09-0.81, $p=0.03$, respectively) 
of rheumatologic symptoms or prior diagnosis of CTD. In our cohort, clinical features and outcomes of ILD with an isolated anti-Ro52 were similar to ILD with antiRo52 in combination with myositis-specific antibodies, including the anti-synthetase antibodies. Mortality is high, especially in the context of ICU admission. Use of the SS-A ELISA alone as the diagnostic test for antiRo52 misses a large number of anti-Ro52 positive patients. Dedicated testing for anti-Ro52 may help to phenotype unclassifiable ILD patients, particularly as part of the serologic criteria for IPAF, which may have important prognostic and future therapeutic implications. Further research is needed to assess treatment strategies for ILD in the setting of anti-Ro52 positivity.

\author{
Abbreviations \\ ANA: Antinuclear antibody; CK: Creatine kinase; CT: Computed tomography; \\ CTD: Connect tissue disease; DAD: Diffuse alveolar damage; DM/ \\ PM: Dermatomyositis/polymyositis; FVC: Forced vital capacity; \\ HP: Hypersensitivity pneumonitis; ILD: Interstitial lung disease; \\ IPAF: Idiopathic pneumonia with autoimmune features; IVIG: Intravenous \\ immune globulin; LIP: Lymphocytic interstitial pneumonia; MCTD: Mixed \\ connective tissue disease; NSIP: Non-specific interstitial pneumonia; \\ OP: Organizing pneumonia; PFT: Pulmonary function test; \\ PPFE: Pleuroparenchymal fibroelastosis; RA: Rheumatoid arthritis; \\ SLE: Systemic lupus erythematosus; UIP: Usual interstitial pneumonia
}

\section{Acknowledgements}

Not applicable.

\section{Take home message}

ILD patients with anti-Ro52 antibodies are similar to patients with myositisspecific antibodies, have high ICU mortality, and may be missed with SS-A testing via ELISA. Dedicated anti-Ro52 testing helps classify ILD patients as part of IPAF criteria.

\section{Authors' contributions}

ASc had full access to all of the data in the study and takes responsibility for the integrity of the data and the accuracy of the data analysis. ASc, KMD, $B P L, E M M, J J L, A S h$, and SBM contributed substantially to the study design, data analysis and interpretation. ASc was the primary author and SBM was a major contributor in writing the manuscript. All authors read and approved the final manuscript.

\section{Funding}

Not applicable.

\section{Availability of data and materials}

The datasets used and/or analyzed during the current study are available from the corresponding author on reasonable request.

\section{Ethics approval and consent to participate}

This study was approved by the Partners Institutional Review Board, protocol \#2010P001906. Subject consent was waived.

\section{Consent for publication}

Not applicable.

\section{Competing interests}

BPL is an academic author for Elsevier and receives royalties for his work. ASh is Principal Investigator for the Hummingbird Inc. study (ClinicalTrials. gov Identifier: NCT03452514). SBM is supported by grants from the Parker B Francis Foundation and Scleroderma Foundation. SBM receives clinical trial support from United Therapeutics paid to her institution. The remaining authors declare no relevant financial disclosures or conflicts of interest.

\section{Author details}

'Division of Pulmonary and Critical Care Medicine, Massachusetts General Hospital and Harvard Medical School, 100 Blossom St, Cox 201, Boston, MA 02114, USA. ${ }^{2}$ Division of Rheumatology, Allergy, and Immunology, Massachusetts General Hospital and Harvard Medical School, Boston, MA, USA. ${ }^{3}$ Department of Radiology, Massachusetts General Hospital and Harvard Medical School, Boston, MA, USA. "Biostatistics Center and Department of Neurology, Massachusetts General Hospital and Harvard Medical School, Boston, MA, USA.

Received: 7 August 2019 Accepted: 1 November 2019 Published online: 12 November 2019

\section{References}

1. Saketkoo LA, Ascherman DP, Cottin V, Christopher-Stine L, Danoff SK, Oddis CV. Interstitial lung disease in idiopathic inflammatory myopathy. Curr Rheumatol Rev. 2010;6(2):108-19.

2. Chen I-J, Jan Wu Y-J, Lin C-W, et al. Interstitial lung disease in polymyositis and dermatomyositis. Clin Rheumatol. 2009;28(6):639-46. https://doi.org/10. 1007/s10067-009-1110-6.

3. Hallowell RW, Danoff SK. Interstitial lung disease associated with the idiopathic inflammatory myopathies and the antisynthetase syndrome. Curr Opin Rheumatol. 2014;26(6):684-9. https://doi.org/10.1097/BOR. 0000000000000104.

4. Hallowell R, Ascherman D, Danoff S. Pulmonary manifestations of Polymyositis/Dermatomyositis. Semin Respir Crit Care Med. 2014;35(02):23948. https://doi.org/10.1055/s-0034-1371528.

5. Won Huh J, Soon Kim D, Keun Lee C, et al. Two distinct clinical types of interstitial lung disease associated with polymyositis-dermatomyositis. Respir Med. 2007;101(8):1761-9. https://doi.org/10.1016/..rmed.2007.02.017.

6. Hamaguchi Y, Fujimoto M, Matsushita T, et al. Common and distinct clinical features in adult patients with anti-aminoacyl-tRNA synthetase antibodies: heterogeneity within the syndrome. PLoS One. 2013;8(4):e60442. https://doi. org/10.1371/journal.pone.0060442.

7. Shi J, Li S, Yang H, et al. Clinical profiles and prognosis of patients with distinct Antisynthetase autoantibodies. J Rheumatol. 2017;44(7):1051-7. https://doi.org/10.3899/jrheum.161480.

8. Solomon J, Swigris JJ, Brown KK. Myositis-related interstitial lung disease and antisynthetase syndrome. J Bras Pneumol. 2011;37(1):100-9.

9. Satoh M, Tanaka S, Ceribelli A, Calise SJ, Chan EKL. A comprehensive overview on myositis-specific antibodies: new and old biomarkers in idiopathic inflammatory myopathy. Clin Rev Allergy Immunol. 2017;52(1):119. https://doi.org/10.1007/s12016-015-8510-y.

10. Cassius $\mathrm{C}$, Le Buanec H, Bouaziz J-D, Amode R. Biomarkers in Adult Dermatomyositis: Tools to Help the Diagnosis and Predict the Clinical Outcome. J Immunol Res. 2019;2019(9, article s139):9141420-15. https://doi. org/10.1155/2019/9141420

11. Vuillard C, de Chambrun MP, de Prost N, et al. Clinical features and outcome of patients with acute respiratory failure revealing anti-synthetase or anti-MDA-5 dermato-pulmonary syndrome: a French multicenter retrospective study. Ann Intensive Care. 2018;8(1):755. https://doi.org/10. 1186/s13613-018-0433-3.

12. Casciola-Rosen L, Mammen AL. Myositis autoantibodies. Curr Opin Rheumatol. 2012;24(6):602-8. https://doi.org/10.1097/BOR. Ob013e328358bd85.

13. Dugar M, Cox S, Limaye V, Gordon TP, Roberts-Thomson PJ. Diagnostic utility of anti-Ro52 detection in systemic autoimmunity. Postgrad Med J. 2010;86(1012):79-82. https://doi.org/10.1136/pgmj.2009.089656.

14. Frank MB, McCubbin V, Trieu E, Wu Y, Isenberg DA, Targoff IN. The association of anti-Ro52 autoantibodies with myositis and scleroderma autoantibodies. J Autoimmun. 1999;12(2):137-42. https://doi.org/10.1006/ jaut.1998.0265.

15. Koenig M, Fritzler MJ, Targoff IN, Troyanov Y, Senécal J-L. Heterogeneity of autoantibodies in 100 patients with autoimmune myositis: insights into clinical features and outcomes. Arthritis Res Ther. 2007;9(4):R78. https://doi. org/10.1186/ar2276.

16. Rutjes SA, Vree Egberts WT, Jongen P, Van Den Hoogen F, Pruijn GJ, Van Venrooij WJ. Anti-Ro52 antibodies frequently co-occur with anti-Jo-1 antibodies in sera from patients with idiopathic inflammatory myopathy. Clin Exp Immunol. 1997;109(1):32-40. https://doi.org/10.1046/j.1365-2249. 1997.4081308.x. 
17. Yamasaki Y, Satoh M, Mizushima M, et al. Clinical subsets associated with different anti-aminoacyl transfer RNA synthetase antibodies and their association with coexisting anti-Ro52. Mod Rheumatol. 2016;26(3):403-9. https://doi.org/10.3109/14397595.2015.1091155.

18. Fiorentino D, Chung L, Zwerner J, Rosen A, Casciola-Rosen L. The mucocutaneous and systemic phenotype of dermatomyositis patients with antibodies to MDA5 (CADM-140): a retrospective study. J Am Acad Dermatol. 2011;65(1):25-34. https://doi.org/10.1016/j.jaad.2010.09.016.

19. La Corte R. Mo Naco Lo a, Locaputo a, Dolzani F, Trotta F. in patients with antisynthetase syndrome the occurrence of anti-Ro/SSA antibodies causes a more severe interstitial lung disease. Autoimmunity. 2006;39(3):249-53. https://doi.org/10.1080/08916930600623791.

20. Váncsa A, Csípo I, Németh J, Dévényi K, Gergely L, Dankó K. Characteristics of interstitial lung disease in SS-A positive/Jo-1 positive inflammatory myopathy patients. Rheumatol Int. 2009;29(9):989-94. https://doi.org/10. 1007/s00296-009-0884-9.

21. Ferreira JP, Almeida I, Marinho A, Cerveira C, Vasconcelos C. Anti-Ro52 antibodies and interstitial lung disease in connective tissue diseases excluding scleroderma. ISRN Rheumatol. 2012;2012(5):1-4. https://doi.org/10.5402/2012/415272.

22. Schulte-Pelkum J, Fritzler M, Mahler M. Latest update on the Ro/SS-A autoantibody system. Autoimmun Rev. 2009;8(7):632-7. https://doi.org/10. 1016/j.autrev.2009.02.010

23. Robbins A, Hentzien M, Toquet S, et al. Diagnostic utility of separate antiRo60 and anti-Ro52/TRIM21 antibody detection in autoimmune diseases. Front Immunol. 2019;10:444. https://doi.org/10.3389/fimmu.2019.00444.

24. Ghillani P, André C, Toly C, et al. Clinical significance of anti-Ro52 (TRIM21) antibodies non-associated with anti-SSA 60kDa antibodies: results of a multicentric study. - PubMed - NCBI. Autoimmun Rev. 2011;10(9):509-13. https://doi.org/10.1016/j.autrev.2011.03.004.

25. Travis WD, Costabel U, Hansell DM, et al. An official American Thoracic Society/European Respiratory Society statement: update of the international multidisciplinary classification of the idiopathic interstitial pneumonias. Am J Respir Crit Care Med. 2013;188(6):733-48. https://doi.org/10.1164/rccm. 201308-1483ST.

26. van den Hoogen F, Khanna D, Fransen J, et al. 2013 classification criteria for systemic sclerosis: an American College of Rheumatology/European league against rheumatism collaborative initiative. Arthritis Rheum. 2013;65(11): 2737-47. https://doi.org/10.1002/art.38098.

27. Shiboski CH, Shiboski SC, Seror R, et al. 2016 American College of Rheumatology/European league against rheumatism classification criteria for primary Sjögren's syndrome. Ann Rheum Dis. 2016;76(1):9-16. https:// doi.org/10.1136/annrheumdis-2016-210571.

28. Petri M, Orbai A-M, Alarcón GS, et al. Derivation and validation of the systemic lupus international collaborating clinics classification criteria for systemic lupus erythematosus. Arthritis Rheum. 2012;64(8):2677-86. https:// doi.org/10.1002/art.34473.

29. Aletaha D, Neogi T, Silman AJ, et al. 2010 rheumatoid arthritis classification criteria: an American College of Rheumatology/European league against rheumatism collaborative initiative. Arthritis Rheum. 2010;62(9):2569-81. https://doi.org/10.1002/art.27584.

30. Alarcon-Segovia D, Villareal M. Classification and diagnostic criteria for mixed connective tissue disease. In: Kasukawa R, Sharp G, editors. Mixed connective tissue disease and anti-nuclear antibodies. Amsterdam: Elsevier; 1987.

31. Lundberg IE, Tjärnlund A, Bottai M, et al. 2017 European league against rheumatism/American College of Rheumatology Classification Criteria for adult and juvenile idiopathic inflammatory myopathies and their major subgroups. Arthritis Rheum. 2017;69(12):2271-82. https://doi.org/10.1002/art.40320.

32. Dasgupta B, Cimmino MA, Maradit-Kremers H, et al. 2012 provisional classification criteria for polymyalgia rheumatica: a European league against rheumatism/ American College of Rheumatology collaborative initiative. Ann Rheum Dis. 2012; 71(4):484-92. https://doi.org/10.1136/annrheumdis-2011-200329.

33. Fischer A, Collard HR, Swigris JJ, et al. An official European Respiratory Society/American Thoracic Society research statement: interstitial pneumonia with autoimmune features. Eur Respir J. 2015;46(4):1-12. https:// doi.org/10.1183/13993003.00150-2015.

34. Koreeda Y, Higashimoto I, Yamamoto M, et al. Clinical and pathological findings of interstitial lung disease patients with anti-aminoacyl-tRNA synthetase autoantibodies. Intern Med. 2010:49(5):361-9.

35. Infantino $M$, Palterer $B$, Biagiotti $R$, et al. Reflex testing of speckled cytoplasmic patterns observed in routine ANA HEp-2 indirect immunofluorescence with a multiplex anti-synthetase dot-blot assay: a multicentric pilot study. Immunol Res. 2018;66(1):74-8. https://doi.org/10. 1007/s12026-017-8974-3.

36. Wilfong EM, Lentz RJ, Guttentag A, et al. Interstitial pneumonia with autoimmune features: an emerging challenge at the intersection of rheumatology and pulmonology. Arthritis Rheum. 2018;70(12):1901-13. https://doi.org/10.1002/art.40679.

37. Novikov P, Shchegoleva E, Akulkina L, Bulanov N, Vinogradova E, Moiseev S. Diagnostic pitfalls and treatment challenges in interstitial pneumonia with autoimmune features: comment on the article by Wilfong et al. Arthritis Rheum. 2018;70:1901. https://doi.org/10.1002/art.40783.

38. Bellani G, Laffey JG, Pham T, et al. Epidemiology, patterns of care, and mortality for patients with acute respiratory distress syndrome in intensive care units in 50 countries. JAMA. 2016;315(8):788-800. https://doi.org/10. 1001/jama.2016.0291.

39. Gannon WD, Lederer DJ, Biscotti M, et al. Outcomes and mortality prediction model of critically ill adults with acute respiratory failure and interstitial lung disease. - PubMed - NCBI. Chest. 2018;153(6):1387-95. https://doi.org/10.1016/j.chest.2018.01.006.

40. Garberg H, Jonsson R, Brokstad KA. The serological pattern of autoantibodies to the Ro52, Ro60, and La48 autoantigens in primary Sjögren's syndrome patients and healthy controls. Scand J Rheumatol. 2005;34(1):49-55.

\section{Publisher's Note}

Springer Nature remains neutral with regard to jurisdictional claims in published maps and institutional affiliations.
Ready to submit your research? Choose BMC and benefit from:

- fast, convenient online submission

- thorough peer review by experienced researchers in your field

- rapid publication on acceptance

- support for research data, including large and complex data types

- gold Open Access which fosters wider collaboration and increased citations

- maximum visibility for your research: over $100 \mathrm{M}$ website views per year

At BMC, research is always in progress.

Learn more biomedcentral.com/submissions 